Gut, 1967, 8, 618

\title{
Surface area of the small intestine in man
}

\author{
J. P. WILSON
}

From the Bland Sutton Institute of Pathology, Middlesex Hospital Medical School, London

EDITORIAL COMMENT This paper sets out the principles for measuring the surface area of small intestine and demonstrates that it decreases sharply from proximal to distal intestine.

Despite wide interest in the small intestine brought about by modern biopsy techniques and absorption studies, quantitative knowledge of the basic structure of the small intestine remains slight.

The irregularity of the mucosal surface caused by the villi and the submucosal folds increases the area available for absorption. The size and distribution of the villi and folds vary from one end of the intestine to the other and there is, therefore, a variation in mucosal area per centimetre length along the intestine.

Early attempts were made to estimate mucosal surface area by measuring and counting individual villi. These gave widely varying results (Heidenhain, 1888; Krogh, 1929). A different approach was used by Warren (1939) who compared linear measurements of mucosa and serosa in two planes in the dog. Fisher and Parsons (1950) applied this technique, together with some mathematical refinements, to the rat. No satisfactory figures are available for man, due largely to the difficulty of obtaining postmortem intestine whose mucosa has not been destroyed by autolysis. The development of a technique for fixing the intestine before it is removed from the body (Wilson, 1966) has achieved satisfactory mucosal preservation and made quantitative studies possible in man.

In this study the mucosal area at different levels has been measured in human intestine obtained at necropsy after fixation in situ.

\section{METHODS}

At necropsy, with the minimum of handling, ties were placed around the proximal jejunum and terminal ileum. A T-shaped cannula was tied into the most prominent presenting loop of intestine and the gut distended to a pressure of $40 \mathrm{~cm} . \mathrm{H}_{2} \mathrm{O}$ with $40 \%$ formaldehyde. After leaving the gut undisturbed for one hour it was removed with its mesentery and placed in formol saline for a further 24 hours. It was then closely shorn of its mesentery, its length measured, and samples cut out at measured intervals from the duodeno-jejunal flexure. From each site two samples, about $4 \mathrm{~cm}$. in length, were taken, one circumferential and one longitudinal. Care was taken to cut the circumferential specimen between and parallel to the submucosal folds.

After embedding in paraffin, histological sections were cut at a thickness of $5 \mu$ and stained with haematoxylin and eosin. Sections were then projected at a linear magnification of 100 on to tracing paper and the outlines of mucosa, muscularis mucosae, and serosa traced in pencil. Measurements of the tracings were made with an opisometer calibrated in centimetres.

Material from six necropsies was studied. The causes of death were renal failure, carcinoma of the bronchus, vulva, and kidney, and, in two cases, myocardial ischaemia. Ages ranged from 38 to 81 .

\section{THE MODIFIED FORMULA}

Man differs from all other animals in having submucosal folds which cannot be flattened by distension (Hilton, 1901). They are fixed structures each containing a core of muscularis mucosae and submucosa. They present a series of transverse ridges projecting into the lumen, and although some form crescents, most have the form of a complete annulus encircling the gut. In developing a formula that can be used in practice two assumptions have had to be made. First, it is assumed that the folds are strictly circumferential in a plane at right angles to the long axis of the gut, and secondly that each fold encountered in a longitudinal section forms a complete annulus.

Fisher and Parsons derived from first principles the following expression for the ratio of mucosal area to serosal area in the rat. 
$\mathbf{R a}=$

$\frac{(\mathrm{ML}-\mathrm{SL})(\mathrm{SC}-\mathrm{NC})+(\mathrm{MC}-\mathrm{SC})(\mathrm{SL}-\mathrm{NL})}{\mathrm{SC} . \mathrm{SL}}+1$

where: $\mathbf{R a}=$ ratio of mucosal area to serosal area

ML = length of mucosal tracing in longitudinal section

SL = length of serosal tracing in longitudinal section

$\mathrm{MC}=$ length of mucosal tracing in circumferential section

$\mathrm{SC}=$ length of serosal tracing in circumferential section

$\mathrm{NL}=7$ length of mucosal tracing and

$\mathrm{NC}=\left\{\begin{array}{l}\text { occupied by villi in longitudinal not } \\ \text { circumferential sections }\end{array}\right.$

In the rat the increase in mucosal area is accounted for by villi. In man the submucosal folds must also be taken into account (Fig. 1). It can be seen that the expression derived by Fisher and Parsons could be applied, in man, to the ratio of mucosal area to submucosal area.

If $\mathrm{q}=$ submucosal tracing in longitudinal section,

$\mathrm{Rq}=$ ratio of mucosal area to submucosal area.

Then:

$$
\begin{aligned}
& \mathrm{Rq}= \\
& \frac{(M L-q)(S C-N C)+(M C-S C)(q-N L)}{S C \cdot q}+1
\end{aligned}
$$

In order to determine the ratio of submucosal to serosal area it is necessary to measure the height of each annulus met with in longitudinal section.

$$
\text { If } \begin{aligned}
\mathrm{Rs}= & \text { the ratio of submucosal area to } \\
& \text { serosal area, } \\
x, y, z= & \text { the heights of individual submucosal } \\
& \text { folds, } \\
\mathrm{r}= & \text { the radius of the intestine. }
\end{aligned}
$$

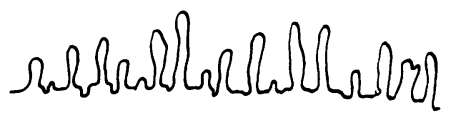

Rat

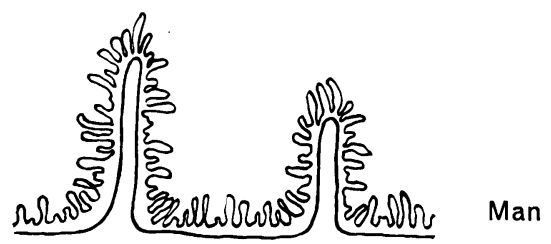

FIG. 1. Diagram of longitudinal sections of rat and human intestine showing submucosal folds in the human.
Then:

$$
\begin{aligned}
& \text { The area of each fold }=2\left[\pi \mathrm{r}^{2}-\pi(\mathrm{r}-x)^{2}\right] \\
& =2 \mathrm{SC} x-2 \pi x^{2}
\end{aligned} \begin{array}{r}
\text { The sum of the folds }=2 \mathrm{SC} \Sigma x-2 \pi \Sigma x^{2} \\
\text { Rs }=\frac{\text { SC.SL }+2 \mathrm{SC} \Sigma x-2 \pi \Sigma x^{2}}{\text { SC.SL }}
\end{array}
$$

The ratio of mucosal to serosal area ( $\mathrm{Ra}$ ) now becomes:

$$
\mathbf{R a}=\mathbf{R q} \cdot \mathbf{R s}
$$

and the mucosal area per unit serosal length (Ma) becomes:

$$
\mathrm{Ma}=\frac{\mathrm{C} \cdot \mathrm{Ra}}{\mathrm{g}}
$$

\begin{tabular}{|c|c|c|c|c|c|c|}
\hline $\begin{array}{l}\text { Distance } \\
\text { from } \\
\text { Duodeno- } \\
\text { jejunal } \\
\text { Flexure } \\
(\mathrm{cm} .)\end{array}$ & $\begin{array}{c}\text { Percentage } \\
\text { Distance } \\
\text { from } \\
\text { Duodeno- } \\
\text { jejunal } \\
\text { Flexure to } \\
\text { lleo-caecal } \\
\text { Valve }\end{array}$ & $C_{(\mathrm{cm} .)}$ & $R q$ & Rs & $R a$ & $M a_{\left(\mathrm{cm} .{ }^{2}\right)}$ \\
\hline $\begin{array}{r}60 \\
180 \\
360 \\
480\end{array}$ & $\begin{array}{l}11 \\
33 \\
66 \\
88\end{array}$ & $\begin{array}{r}11.04 \\
9.66 \\
9.48 \\
9.58\end{array}$ & $\begin{array}{l}3 \cdot 08 \\
2 \cdot 78 \\
2 \cdot 44 \\
2 \cdot 20\end{array}$ & $\begin{array}{l}1 \cdot 81 \\
1 \cdot 38 \\
1 \cdot 22 \\
1 \cdot 13\end{array}$ & $\begin{array}{l}6.66 \\
3.83 \\
2 \cdot 97 \\
2.48\end{array}$ & $\begin{array}{l}73 \cdot 52 \\
36.99 \\
28 \cdot 15 \\
23 \cdot 75\end{array}$ \\
\hline \multicolumn{3}{|c|}{$\begin{array}{l}\text { Total gut length }=550 \mathrm{~cm} . \\
\text { Total mucosal area }=2.2 \mathrm{m.}^{2}\end{array}$} & \multicolumn{2}{|c|}{$\begin{array}{l}\text { Height } \\
\text { Weight } \\
\text { Surface ar }\end{array}$} & \multicolumn{2}{|c|}{$\begin{aligned} & =170 \mathrm{~cm} . \\
& =51 \mathrm{~kg} . \\
& =1.58 \mathrm{~m} .\end{aligned}$} \\
\hline
\end{tabular}

where $\mathrm{g}$ is the magnification factor, and $\mathrm{C}$ is the serosal circumference of the intestine.

\section{RESULTS}

The Table shows detailed results from one case. Since gut length is so variable, sites of sampling are expressed as percentage distance from duodenojejunal flexure to ileo-caecal valve.

TABLE

DETAILED RESULTS FROM ONE CASE AT DIFFERENT LEVELS BETWEEN THE DUODENO-JEJUNAL FLEXURE AND THE ILEOCAECAL VALVE

Mucosal areas per unit length at different levels calculated from all six cases are shown in Figure 2. The fall off in mucosal area from proximal to distal intestine is initially rapid, so that almost half of the total mucosal area is found in the proximal quarter of the gut. A straight line is obtained when the distance is plotted against $\log _{e} \sqrt{\mathrm{Ma}}$. The best fitting line has the equation:

$$
\log _{e} \sqrt{\mathrm{Ma}}=2.34-0.009 x
$$

Figure 3 shows the gradient of the ratios of mucosal area to submucosal area. This represents the increase in area due to the villi alone. The points lie reasonably on a straight line. The best fitting line has the equation:

$$
\mathrm{Rq}=4 \cdot 179-0.023 x
$$




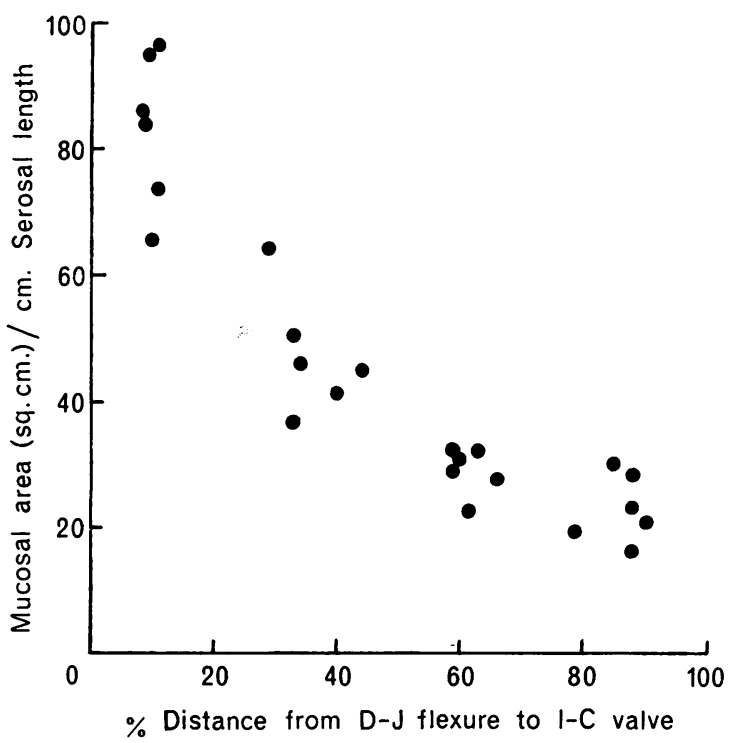

FIG. 2. Mucosal area estimates at different intestinal levels (correlation coefficient $r=0.91$ ).

\section{SYSTEMATIC ERRORS}

The extent of shrinkage resulting from fixation and embedding was studied. Measurement of gut length and circumference before fixation and 24 hours after distension with $40 \%$ formaldehyde showed a shrinkage of $3.5 \%$. Measurement of the circum-

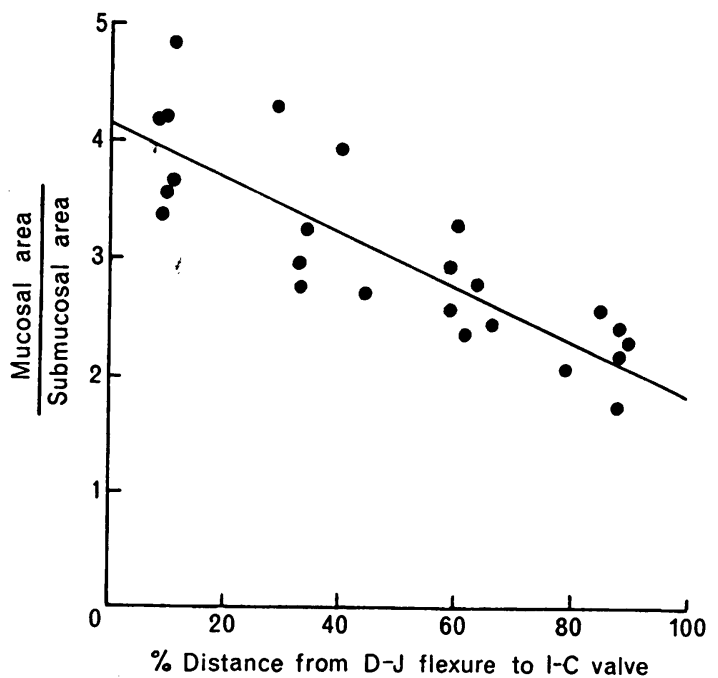

FIG. 3. Ratio of mucosal and submucosal areas at the same sites as in Figure 2 (correlation coefficient $r=0.84$; $y=4 \cdot 179-0 \cdot 023 x)$. ference of fixed intestine before and after embedding showed a further shrinkage of $9 \%$. The results presented have been corrected for these systematic errors.

\section{DISCUSSION}

Clear-cut gradients of area from proximal to distal intestine have been demonstrated in the pigeon (Verzár and McDougall, 1936), dog (Warren, 1939), cat (Wood, 1944), and rat (Fisher and Parsons, 1950). In all of these a straight line gradient has been shown similar to that for the ratio of mucosa to submucosa in man. When the submucosal folds are also taken into account the gradient in man is found to be much steeper in the jejunum than in the ileum.

It has been suggested (Flint, 1912; Cori, 1925) that absolute values for mucosal surface area would bear a direct relation to body weight. The relation between the total mucosal surface areas of the six cases on the one hand, and body weight and body surface on the other, shown in Fig. 4, tend to support this view.

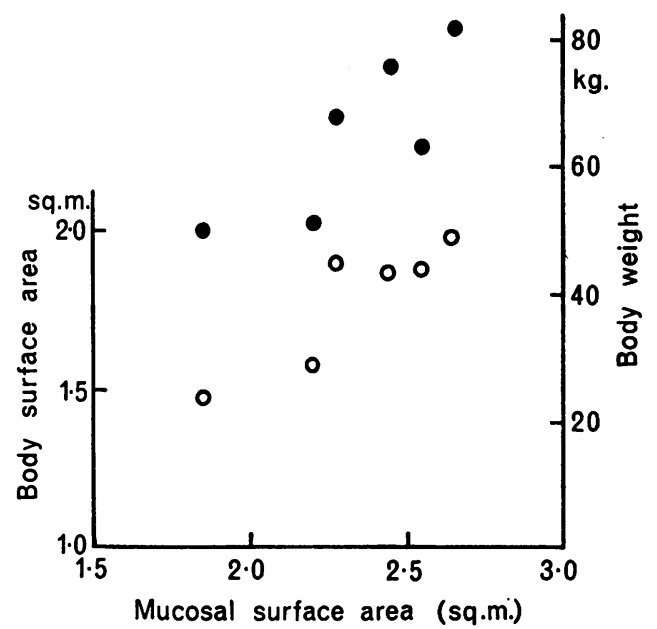

FIG. 4. Total mucosal area estimates from the six cases plotted against body surface area, $\bigcirc$ (calculated from the formula of Dubois and Dubois), and body weight, 0.

In this study no account has been taken of the duodenum whose surface irregularity is quite as great as that of the jejunum. No account, either, has been taken of the microvilli, although Spencer (1961) suggests that they may increase the surface area fifteenfold.

\section{SUMMARY}

Histological measurements in two planes of human 
small intestine have been used to estimate the mucosal surface area at different intestinal levels.

The development of a technique for preserving small intestine has made post-mortem material available for this study.

The six cases studied demonstrate that surface area decreases sharply from proximal to distal intestine.

I am grateful to Miss Margaret Hill who helped to prepare the histological sections.

\section{REFERENCES}

Cori, C. F. (1925). The fate of sugar in the animal body. 1. The rate of absorption of hexoses and pentoses from intestinal tract. J. biol. Chem., 66, 691-715.
Fisher, R. B., and Parsons, D. S. (1950). The gradient of mucosal surface area in the small intestine of the rat. J. Anat. (Lond.), 84, 272-282.

Flint, J. M. (1912). The effect of extensive resections of the small intestine. Bull. Johns Hopk. Hosp., 23, 125-144.

Heidenhain, R. (1888). Beitrăge zu Histologie u. Physiologie der Dünndarmschleimhaut. Pfüger's Arch. ges. Physiol., Supplementheft Vol. 43.

Hilton, W. A. (1901). The morphology and development of intestinal folds and villi in vertebrates. Amer. J. Anat., 1, 459-491.

Krogh, A. (1929). The Anatomy and Physiology of Capillaries, 2nd ed. Yale University Press, New Haven.

Spencer, R. P. (1961). Microvilli and intestinal surface area; an evaluation. Gastroenterology, 41, 313-314.

Verzár, F., and McDougall, E. J. (1936). Absorption from the Intestine. Longmans, Green, London.

Warren, R. (1939). Serosal and mucosal dimensions at different levels of the dog's small intestine. Anat. Rec., 75, 427-437.

Wilson, J. P. (1966). Post-mortem preservation of the small intestine. J. Path. Bact., 92, 229-230.

Wood, H. O. (1944). The surface area of the intestinal mucosa in the rat and in the cat. J. Anat. (Lond.), 78,103-105. 